\title{
Nephrogenic Fibrosing Dermopathy
}

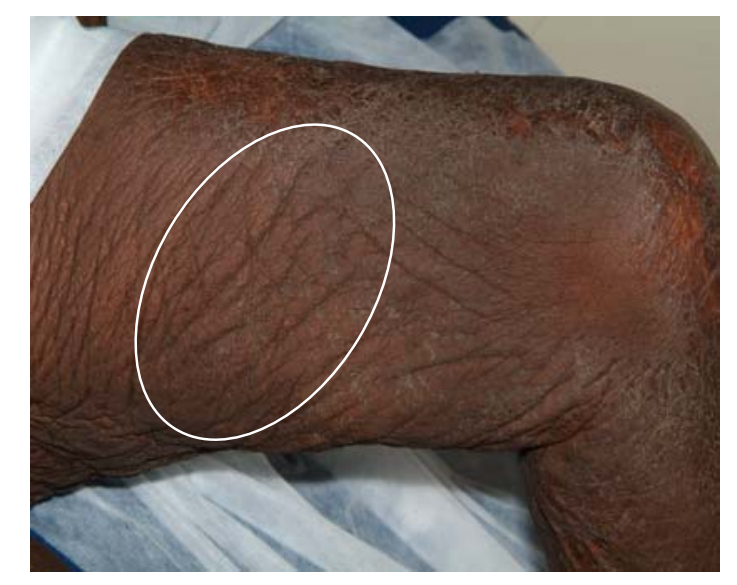

Thickening and puckering of skin commonly affecting the thigh area.

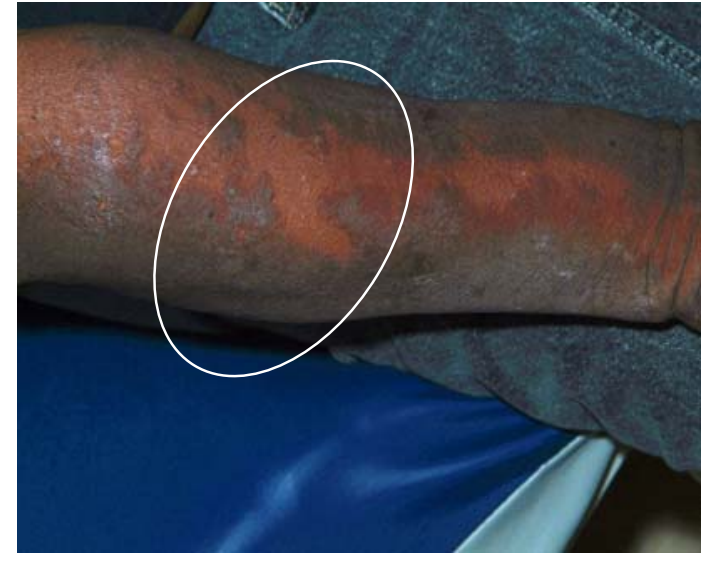

Erythema with skin tightening and hyperpigmented plaques.

\author{
Ashish Dhungel*, Rakesh Lattupalli, and Joel Topf \\ Division of Nephrology, St. John Hospital and Medical Center, Detroit, MI \\ E-mail: Ashish.Dhungel@stjohn.org
}

Received December 12, 2007; Accepted December 12, 2007; Published February 6, 2008

KEYWORDS: nephrogenic fibrosing dermopathy, dialysis, gadolinium

A 50-year-old, African American female was admitted with acute kidney injury from acute allograft rejection and underwent MRI (magnetic resonance imaging) with gadolinium. Hemodialysis was initiated secondary to graft failure 2 days later. Over the next 30 days, skin tightening was noticed initially in the lower extremities, which gradually progressed to involve the back and upper limbs. Ankle and knee joints developed contractures, leading to immobility. Skin biopsy revealed dermal sclerosis with fibrocytic proliferation, consistent with nephrogenic fibrosing dermopathy (NFD). NFD is an uncommon, but increasingly recognized, skin condition observed in patients with renal failure who were exposed to gadolinium.

\section{REFERENCES}

1. $\quad$ Cowper, S.E., Su, L., Robin, H., Bhawan, J., and LeBoit, P.E. (2001) Nephrogenic fibrosing dermopathy. Am. J. Dermatopathol. 23, 383-393. 
2. http://www.fda.gov/cder/drug/advisory/gadolinium_agents_20061222.htm [U.S. Food and Drug Administration. Center for Drug Evaluation and Research. Public Health Advisory. Update on Magnetic Resonance Imaging (MRI) Contrast Agents Containing Gadolinium and Nephrogenic Fibrosing Dermopathy.

\section{This article should be cited as follows:}

Dhungel, A., Lattupalli, R., and Topf, J. (2008) Nephrogenic fibrosing dermopathy. TheScientificWorldJOURNAL 8, $164-165$. DOI 10.1100/tsw.2008.28. 


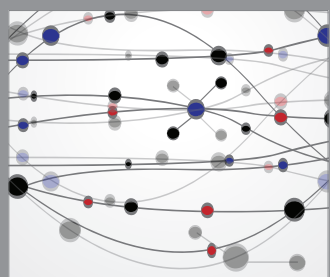

The Scientific World Journal
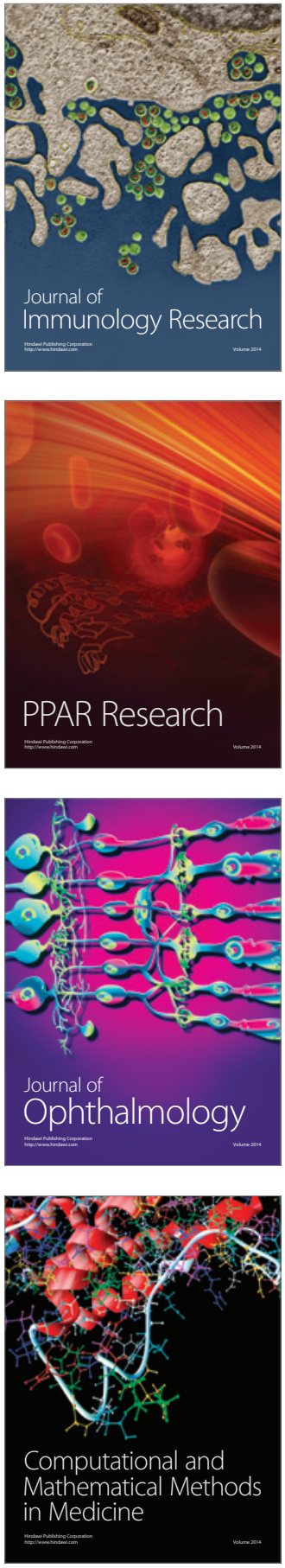

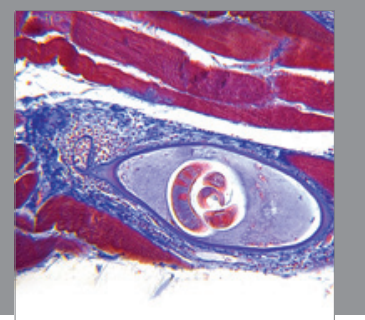

Gastroenterology

Research and Practice
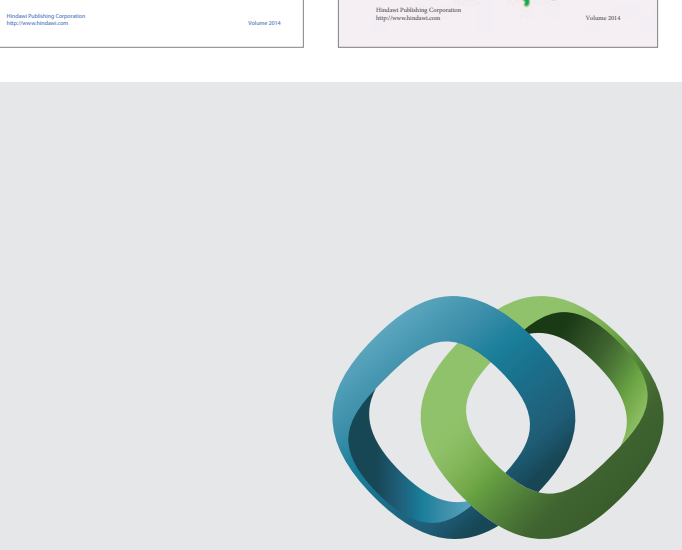

\section{Hindawi}

Submit your manuscripts at

http://www.hindawi.com
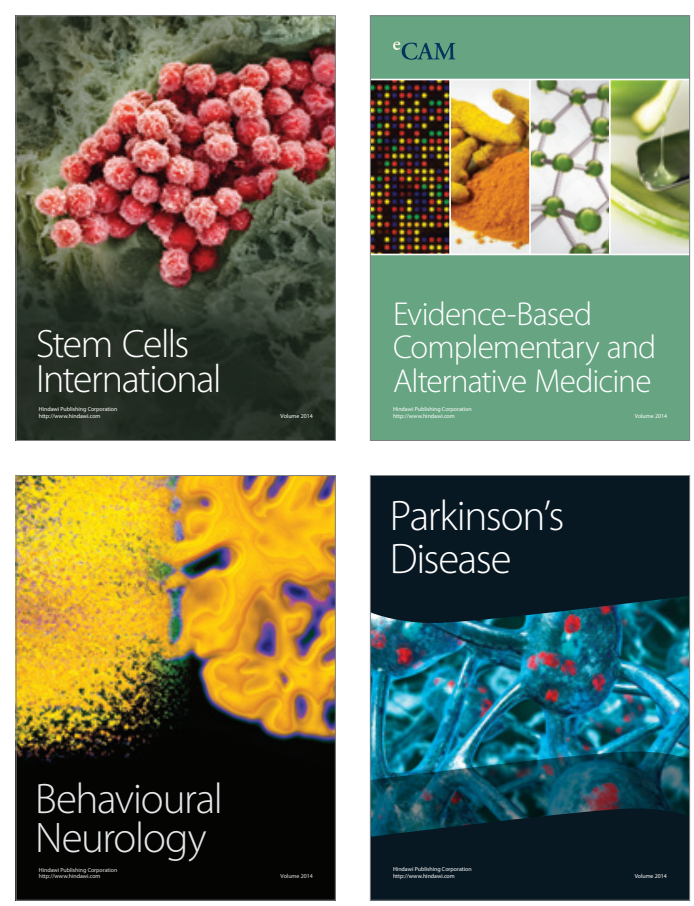

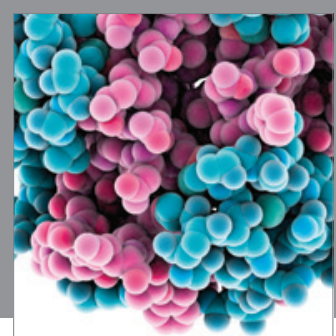

Journal of
Diabetes Research

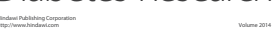

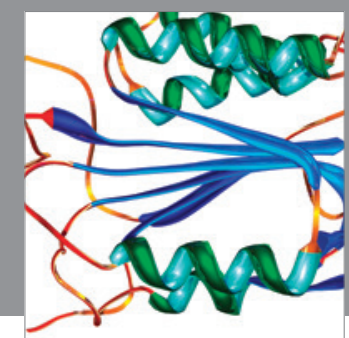

Disease Markers
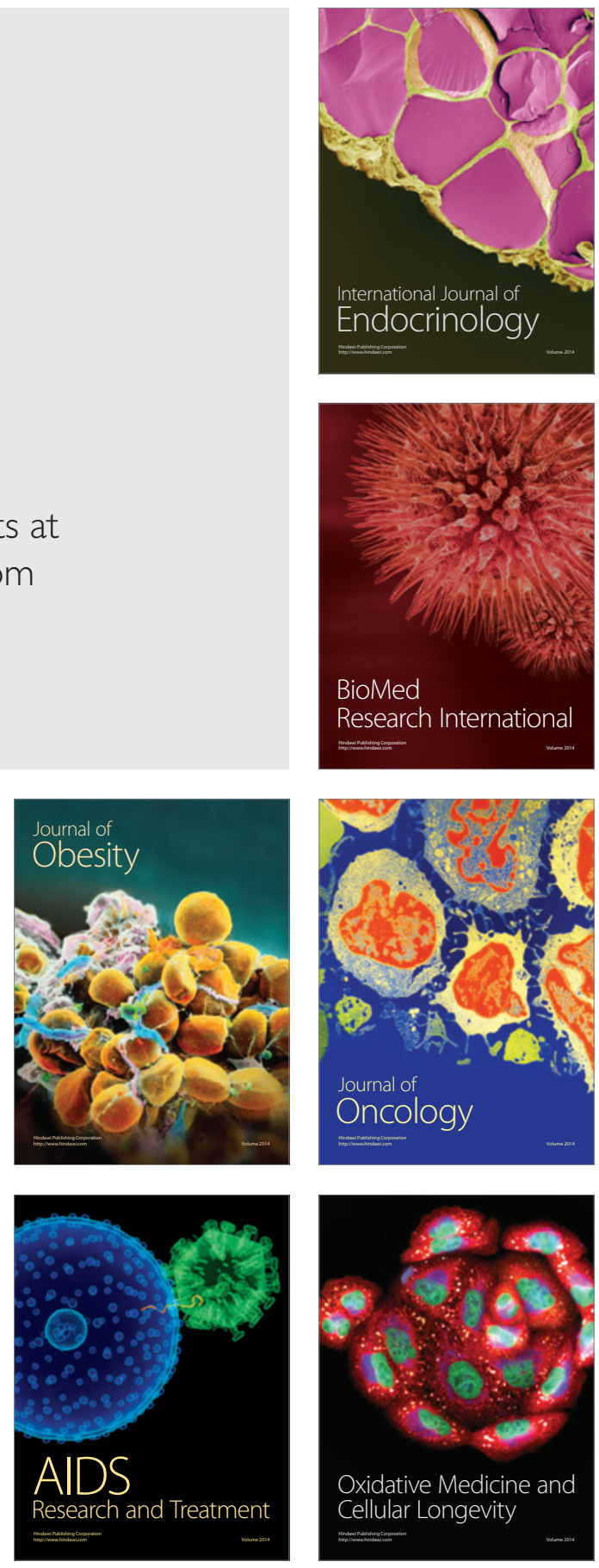